\title{
Escala de Identificação de Dotação e Talento: Estrutura e Consistência Internas
}

\author{
Márcia de Fátima Rabello Lovisi de Freitas - Universidade Federal de São Carlos, São Carlos, Brasil \\ Patrícia Waltz. Schelini - Universidade Federal de São Carlos, São Carlos, Brasil \\ Edgardo Raúl Pérez - Universidad Nacional de Córdoba, Córdoba, Argentina
}

\begin{abstract}
Resumo
O estudo objetivou analisar a precisão e as evidências de validade com base na estrutura interna da Escala de Identificação de Dotação e Talento (EIDT). A EIDT é respondida por docentes dos $4^{\circ}, 5^{\circ}$ e $6^{\circ}$ anos do Ensino Fundamental, sendo que participaram da pesquisa 16 professores, que avaliaram 433 alunos. Os resultados indicaram que 54,8\% da variância foi explicada. Por meio da análise fatorial exploratória, a versão final da escala ficou composta por 55 itens divididos em três fatores: 42 itens do Fator 1, capacidades intelectuais, sociais e criatividade; sete do Fator 2, capacidades psicomotoras e seis do Fator 3, capacidades artísticas. O alfa de Cronbach para a escala total foi de 0,97. O Fator 1 apresentou um alfa de 0,97, o Fator 2 de 0,89 e o Fator 3 de 0,83 . Destaca-se a necessidade de estudos adicionais que incluam a análise fatorial confirmatória e o estabelecimento de normas.

Palavras-chave: superdotados, testes psicológicos, psicometria
\end{abstract}

Scale of Giftedness and Talent Identification: Internal Structural and Consistency

\begin{abstract}
The study aimed to analyze the reliability and the evidences of validity based on the internal structure of the Scale of Giftedness and Talent Identification (Escala de Identificação de Dotação e Talento - EIDT). The EIDT is answered by teachers of 4th, 5th and 6th years of elementary school, including 16 teachers who evaluated 433 students. The results indicated that $54.8 \%$ of the variance was explained. Exploratory factor analysis was used for the final version of the scale, which was composed of 55 items divided into three factors: 42 items in Factor 1, intellectual abilities, social abilities and creativity; seven in factor 2, psychomotor abilities and six in factor 3, artistic abilities. The Cronbach's alpha for the total scale was 0.97. Factor 1 showed an alpha of 0.97 , factor 2 of 0.89 , and factor 3 of 0.83 . It highlights the need for additional studies including the confirmatory factor analysis and the establishment of standards.

Keywords: gifted, psychological testing, psychometrics
\end{abstract}

\section{Escala de Identificación de Dotación y Talento: Estructura y Consistencia Internas}

\begin{abstract}
Resumen
El objetivo del estudio fue analizar precisión y evidencias de validez basadas en la estructura interna de la Escala de Identificación de Dotación y Talento (EIDT). La EIDT fue respondida por maestros de $4^{\circ}, 5^{\circ}$ y $6^{\circ}$ año de Enseñanza Primaria, y participaron en la investigación 16 profesores que evaluaron a 433 alumnos. Los resultados indicaron que el 54,8\% de la varianza fue explicada. Por medio de análisis factorial exploratorio, la versión final de la escala quedó compuesta por 55 ítems, divididos en tres factores: 42 ítems del factor 1, capacidades intelectuales, sociales y creatividad; 7 ítems del factor 2, capacidades psicomotoras y 6 del factor 3, capacidades artísticas. El alfa de Cronbach para la escala total fue de 0,97. El factor 1 presentó un alfa de 0,97 , el factor 2 de 0,89 y el factor 3 de 0,83 . Se destaca la necesidad de estudios adicionales, que incluyan el análisis factorial confirmatorio y el establecimiento de normas.

Palabras-clave: superdotados, tests psicológicos, psicometría.
\end{abstract}

A legislação brasileira denomina as pessoas com capacidades elevadas em diferentes áreas como portadores de altas habilidades/superdotação (Brasil, 2001). Todavia, tais termos tendem a fortalecer a concepção ultrapassada de capacidade elevada como algo exclusivamente inato e sem necessidade de desenvolvimento, devido ao uso do termo habilidades ao invés de capacidades e à conotação do termo superdotado no senso comum. Por isso, este trabalho se baseará no conceito de indivíduos com características de dotação e talento (D\&T). Gagné (2013) foi um dos poucos autores da área a teorizar de fato sobre a diferença entre os construtos dotação e talento. De acordo com Gagné (2013), dotação (giftedness) diz respeito à posse e ao uso de capacidades naturais elevadas. Talento (talent) implica no desempenho notável de habilidades que foram sistematicamente desenvolvidas. Sendo assim, o uso do construto composto revela um princípio desenvolvimentista e processual das capacidades elevadas em qualquer área, que não devem ser 
consideradas exclusivamente inerentes aos indivíduos (Horowitz, 2009).

O Modelo de Dotação de Munique - MDM (Heller, 2004, 2005, 2007, 2012; Heller \& Perleth, 2008; Heller, Perleth, \& Lim, 2005) atribui importância fundamental ao processo de desenvolvimento de dotações em talentos e, por isso, compreende o conceito de D\&T da mesma forma que Gagné (2013), apesar da nomenclatura diferenciada. É considerado um modelo multidimensional e desenvolvimental de D\&T (Sternberg \& Davidson, 2005; Stoeger, Steinbach, Obergriesser, \& Matthes, 2014), na medida em que considera o talento como o produto de um processo de aprendizagem sistemático, no qual atuam diversas variáveis.

De acordo com Heller, Perleth e Lim (2005), o MDM engloba características individuais e ambientais em um modelo coerente de D\&T. O que se compreende por dotações, de acordo com a definição apresentada por Gagné (2013), é denominado como preditores ou fatores do talento no MDM. Os preditores consistem em grupos de capacidades relativamente independentes uma das outras e compreendem sete categorias: capacidades intelectuais, criatividade, competência social, inteligência prática, capacidades artísticas, musicalidade e capacidades psicomotoras. Já os talentos, considerando ainda a definição de Gagné (2013), são chamados de variáveis de critério ou áreas de desempenho no MDM. Representam as habilidades observáveis após o processo de desenvolvimento dos preditores, incluindo o desempenho em áreas como matemática, artes, esportes, etc. O processo de desenvolvimento dos preditores em variáveis de critério é mediado por variáveis moderadoras individuais e ambientais, dentre as quais fazem parte motivação, estratégias de aprendizagem, clima familiar e escolar, qualidade do ensino etc. As variáveis moderadoras exercem papel importante nos modelos desenvolvimentais de D\&T, como o MDM, uma vez que podem facilitar ou dificultar o processo de desenvolvimento das dotações em talentos.

Tendo o MDM como pano de fundo teórico, Heller (2004) e Heller e Perleth (2008) propuseram estratégias multidimensionais de identificação de alunos com D\&T que ocorrem em três etapas. Inicialmente, realiza-se um rastreio (screening) da população escolar que se pretende avaliar. Essa primeira etapa pode incluir o preenchimento de checklists pelos professores, pais e/ ou alunos e a observação comportamental dos alunos em sala de aula por especialistas. Deve-se encontrar entre $10 \%$ e $20 \%$ dos avaliados como potencialmente talentosos nesse momento da identificação. $\mathrm{Na}$ segunda etapa, o percentual de alunos indicados como possivelmente talentosos é submetido à aplicação de outras medidas mais específicas, como testes padronizados de inteligência, escalas e questionários que avaliem as diversas variáveis que compõem o modelo. Ao final da segunda etapa, estima-se identificar um percentual de $2 \%$ a $5 \%$ de alunos com características de D\&T, considerando a população inicial avaliada. Nesse momento, cabe ainda a decisão final por quais alunos deverão ser inclú́dos no pool de identificados ou não. O grupo de alunos identificados pode, ainda, passar por avaliações individuais mais detalhadas que os encaminhem a programas de enriquecimento de talentos.

No Brasil, há certa carência de medidas válidas para identificar alunos com D\&T (Barbosa, Schelini, \& Almeida, 2012), quando comparado a outros países. Faltam, principalmente, medidas que avaliem domínios como o psicomotor e o socioemocional, que tendem a ser menos enfatizados por testes padronizados, bem como instrumentos elaborados especificamente para a identificação de características de D\&T. A lacuna se torna ainda maior ao reconhecer que propostas teóricas multidimensionais como o MDM, bem como suas estratégias de identificação, ainda são pouco conhecidas e utilizadas no país. Nakano e Siqueira (2012) traduziram e adaptaram para o contexto brasileiro a Gifted Rating Scale - school form, originalmente elaborada por Pfeiffer e Jarosewich (2003). Essa escala é baseada no MDM (Heller et al., 2005) e na tipologia de talento do Departamento de Educação dos Estados Unidos (Ross, 1993). Todavia, não foi encontrado um instrumento construído exclusivamente para o contexto brasileiro e elaborado fundamentalmente sobre as premissas do MDM.

Por esse motivo, Freitas (2016) elaborou a Escala de Identificação de Dotação e Talento (EIDT). A EIDT é uma escala do tipo Likert de quatro pontos que se propõe a rastrear características de D\&T em alunos do Ensino Fundamental ( $4^{\circ}, 5^{\circ}$ e $6^{\circ}$ anos) por meio da nomeação por professores, atuando como um checklist durante a primeira etapa do processo de identificação proposto por Heller (2004) e Heller e Perleth (2008).

Freitas (2016) descreve as duas primeiras etapas necessárias para a construção do instrumento. $\mathrm{Na}$ primeira etapa, foram elaborados 120 itens que compuseram a primeira versão da EIDT. A elaboração dos itens se fundamentou sobre os sete preditores do talento do MDM. No entanto, os preditores capacidades artísticas e musicalidade foram condensados em uma única 
dimensão durante a construção da escala devido às especificidades do sistema educacional brasileiro, que não costuma desmembrar esses conteúdos em duas disciplinas diferentes, facilitando, portanto, a construção dos itens do fator e a atribuição das respostas pelos professores. Sendo assim, a EIDT foi elaborada a partir de seis domínios: capacidades intelectuais, criatividade, competência social, inteligência prática, capacidades artísticas/musicalidade e capacidades psicomotoras.

A autora destaca, ainda, que não foi encontrada uma operacionalização dos preditores na literatura em inglês disponível sobre o MDM. Por isso, foi necessário fundamentar as definições constitutivas dos domínios da EIDT em outros modelos e perspectivas teóricas que não somente o MDM, de modo a agregar informações teóricas consistentes a cada domínio. Assim, o domínio capacidades intelectuais foi compreendido por meio da teoria das capacidades cognitivas de Cattell-Horn-Carroll ou teoria CHC (Campos \& Nakano, 2012; McGrew, 2009; Nisbett et al., 2012), o domínio criatividade por meio do modelo de criatividade de Torrance (Kim, 2011) e o domínio competência social por meio das teorias sobre inteligência emocional e habilidades sociais (Topping, Bremner, \& Holmes, 2002; França-Freitas, Del Prette, \& Del Prette, 2014). Já os domínios capacidades artísticas/musicalidade e capacidades psicomotoras são compreendidos à luz da teoria das inteligências múltiplas de Gardner (Gardner, Chen, \& Moran, 2010) e o domínio inteligência prática de acordo com a teoria triárquica de Sternberg (Hedlund \& Sternberg, 2002).

As definições constitutivas elaboradas para cada um dos seis domínios da EIDT, de acordo com Freitas (2016), são: 1) capacidades intelectuais: envolvem inteligência fluida, inteligência cristalizada, memória de curto e longo prazo, rapidez de raciocínio ou tempo de reação, áreas de interesse consolidadas, conhecimentos adiantados e precocidade; 2) criatividade: envolve originalidade, pensamento divergente, fluência, flexibilidade e curiosidade; 3) competência social: definida como o uso eficaz das habilidades sociais, a capacidade de alcançar resultados sociais. Envolve sensibilidade para problemas/empatia, cooperação, adaptabilidade social, cognições sociais e habilidades sociais; 4) inteligência prática: caracteriza-se pelo uso de habilidades intelectuais voltadas a tarefas cotidianas e do senso comum. Envolve automotivação, autorganização em tarefas o dia a dia, administração de relacionamentos pessoais, conhecimento sobre como realizar tarefas específicas, planejamento de atividades, monitoramento do progresso delas e avaliação de resultados; 5) capacidades artísticas/musicalidade: entende-se por capacidades artísticas toda e qualquer capacidade que busca como resultado final uma produção ou expressão artística, seja ela desenho, pintura, dança, música, etc. Musicalidade é definida como a habilidade de perceber e utilizar melodias, timbres e ritmos, de criar, se comunicar e perceber significados através de sons; e 6) capacidades psicomotoras: diz respeito à facilidade de expressão por meio de movimentos corporais. Usar objetos ou utilizar todo o corpo ou partes dele na solução de problemas ou na construção de produtos.

$\mathrm{Na}$ segunda etapa da construção do instrumento, descrita por Freitas (2016), os itens da EIDT foram avaliados por juízes especialistas em D\&T e conhecedores do MDM, que atuaram na validação de conteúdo da escala. Após as análises das respostas dos juízes, a nova versão da EIDT ficou composta de 98 itens, divididos nos mesmos seis domínios, sendo essa versão a que foi aplicada nos professores participantes do presente trabalho. A escala apresentou resultados satisfatórios quanto às evidências de validade baseadas no conteúdo.

O presente trabalho, portanto, faz uso da EIDT (Freitas, 2016) para suprir uma lacuna existente na identificação de alunos com D\&T no Brasil, contribuindo para uma proposta de avaliação multidimensional que possa levar à promoção de talentos em programas de enriquecimento e desenvolvimento adequados. A EIDT não pretende estabelecer critérios diagnósticos para normatizar quais crianças possuem ou não características de D\&T. Sua função é apenas rastrear características que servem como indicativo da existência de dotações. A identificação de alunos com D\&T deve ser vista como um processo multidimensional amplo, dinâmico e contínuo, como destacado anteriormente. Sendo assim, o objetivo deste estudo foi investigar as evidências de validade baseadas na estrutura interna, bem como as estimativas de precisão com base na consistência interna, de uma escala de nomeação por professores, elaborada por Freitas (2016) para rastrear características de D\&T em alunos de $4^{\circ}, 5^{\circ}$ e $6^{\circ}$ anos do Ensino Fundamental.

\section{Método}

\section{Participantes}

Foram convidados a participar da pesquisa 36 professores dos $4^{\circ}, 5^{\circ}$ e $6^{\circ}$ anos do Ensino Fundamental de oito escolas municipais e estaduais de uma cidade do interior de São Paulo. No entanto, participaram 
efetivamente 16 docentes. Os demais convidados alegaram não ter tempo hábil para contribuir com o estudo. Os 16 professores participantes avaliaram os alunos de suas respectivas turmas, que compuseram uma amostra de 433 discentes avaliados, sendo 228 estudantes do $4^{\circ}$ ano, 122 estudantes do $5^{\circ}$ ano e 83 estudantes do $6^{\circ}$ ano. Do total de docentes participantes, nove ministravam aulas para o $4^{\circ}$ ano, quatro para o $5^{\circ}$ ano e três para o $6^{\circ}$ ano. Ainda considerando estes, 15 eram do sexo feminino e apenas um do sexo masculino.

Dado que as turmas de $4^{\circ}$ e $5^{\circ}$ anos possuem apenas um professor regente, esse foi considerado o respondente da pesquisa. Nas turmas de $6^{\circ}$ ano, como havia professores de diferentes disciplinas, aquele que concordava em participar respondia à escala para avaliação dos alunos. Dos três professores participantes do $6^{\circ}$ ano, um deles ministrava aulas de História, outro, de Matemática e outro, de Artes. Eles ministravam aulas para cada turma, no mínimo, duas vezes por semana. Os professores tinham entre seis e 20 anos de magistério, sendo que todos ministravam aulas nas turmas há nove meses, pelo menos.

\section{Instrumentos}

Foi utilizada a Escala de Identificação de Dotação e Talento (EIDT), elaborada por Freitas (2016). A EIDT é composta por 98 itens, divididos em seis domínios e se propõe a identificar características de D\&T em alunos de $4^{\circ}, 5^{\circ}$ e $6^{\circ}$ anos do Ensino Fundamental, atuando como um instrumento de rastreio. A escala deve ser respondida pelo professor que, após ler o item, atribui um valor entre 1 e 4 para cada aluno avaliado, sendo que 1 equivale a "nunca", 2 a "quase nunca", 3 a "quase sempre" e 4 a "sempre", considerando a frequência do comportamento expresso pelo item. $\mathrm{O}$ professor deve avaliar todos os alunos da turma. Os domínios que compõem a EIDT são: capacidades intelectuais, criatividade, competência social, inteligência prática, capacidades artísticas/musicalidade e capacidades psicomotoras.

Cada docente participante recebeu, juntamente com os itens da escala, uma tabela com o nome de todos os alunos de sua turma e com um espaço para atribuir sua avaliação sobre eles. Foram incluídos, ainda, instruções e exemplos de como preenchê-la e um questionário de caracterização do docente, que continha informações como nome do professor, escola em que trabalha, turma avaliada, há quanto tempo ministra aulas para essa turma, há quanto tempo atua como professor e se há na turma alunos com alguma necessidade educacional especial, além do termo de consentimento livre e esclarecido.

\section{Procedimentos}

O desenvolvimento da pesquisa se iniciou somente após a aprovação do projeto pelo Comitê de Ética em Pesquisas com Seres Humanos da Universidade Federal de São Carlos (CAAE: 08612112.9.0000.5504). Antes da entrega da escala e da avaliação pelos professores, foram feitos esclarecimentos sobre os objetivos da pesquisa e sobre o preenchimento da EIDT durante as reuniões pedagógicas de cada escola participante. Após os esclarecimentos, os professores presentes na reunião que ministrassem aulas para os $4^{\circ}, 5^{\circ}$ e $6^{\circ}$ anos, eram convidados a participarem da pesquisa, e aqueles que aceitavam, já recebiam nesse momento a escala com as instruções e o questionário de caracterização docente. Os professores participantes tiveram cerca de três meses para responder à escala, que foi entregue a eles para que pudesse ser preenchida durante seu tempo livre.

Após o preenchimento e devolução dos instrumentos, os dados foram alocados em um banco de dados do Statistical Package for the Social Sciences (SPSS) versão 17.0 para realização das análises. Salienta-se, ademais, que este estudo respeitou os princípios éticos para pesquisas com seres humanos em todos os seus procedimentos, bem como considerou as diretrizes nacionais (CFP, 2003) e internacionais (ITC, 2000) para elaboração e uso de testes psicológicos.

\section{Resultados e Discussão}

Primeiramente, procedeu-se à verificação de valores omissos, ou seja, itens da escala que não foram respondidos pelos participantes. Optou-se pela substituição dos dados omissos ao invés da exclusão destes, para que as análises posteriores pudessem ser feitas sem prejuízo. A porcentagem de dados omissos foi menor que 3\%. A imputação dos dados foi feita por meio da ferramenta replace missing values, que substitui os valores ausentes pela média de outros casos do item em questão.

Em seguida, foram somadas as pontuações brutas dos itens da escala para cada aluno avaliado e calculados os valores de assimetria e curtose para a soma das pontuações e para cada item, já que a normalidade multivariada é um pressuposto da análise fatorial. Adotou-se como valores aceitáveis $|\mathrm{sk}|<3$ e $|\mathrm{ku}|<8$ 
(Kline, 2005). A EIDT não obteve índices inaceitáveis de assimetria e curtose nas variáveis.

A fim de averiguar a adequação da amostra e das variáveis às análises fatoriais a serem empregadas, utilizaram-se a prova Kaiser-Meyer-Olkin (KMO) e o teste de esfericidade de Bartlett. A prova KMO verificou ótima adequação da amostra à análise (KMO $=0,968)$. $O$ teste de esfericidade de Bartlett $\left(\chi_{0}^{2}=43789,385 ; \mathrm{gl}\right.$ $=4753 ; p<0,001)$ foi altamente significativo e indicou que existem correlações entre os itens suficientes para realização de análises fatoriais. Sendo assim, procedeu-se à primeira análise fatorial exploratória (AFE) da escala.

Foi realizada uma AFE com os 98 itens da EIDT, sem nenhuma rotação, a fim de verificar o número inicial de componentes extraídos. Essa AFE demonstrou que 15 fatores obedecem ao critério de Kaiser do autovalor (eigenvalue) maior que 1 e explicam $75,2 \%$ da variância. Muitos desses fatores extraídos na AFE inicial continham apenas um ou poucos itens saturados, visto que havia grande dispersão dos itens entre os componentes. O scree plot não foi capaz de apontar com clareza o ponto de inflexão que demonstrasse o número de fatores a ser extraído e pareceu indicar que a escala se constituía de um componente unidimensional (o primeiro fator extraído), que explicaria $44,4 \%$ da variância.

Por isso, uma análise paralela foi feita como método para determinar o número de fatores a ser retido na AFE (Horn, 1965; Damásio, 2012). Todavia, a análise paralela não apresentou resultados relevantes teórica e estatisticamente, indicando que poderiam ser extraídos nove fatores. Sendo assim, foram realizadas outras análises de componentes da escala, considerando, sobretudo, a proposta teórica do Modelo de Dotação de Munique - MDM (Heller et al., 2005) que embasa sua construção.

Uma nova análise foi feita, dessa vez solicitandose uma solução de seis fatores, com rotação promax e suprimindo os itens com carga fatorial menor que 0,30 (Prieto \& Muñiz, 2000). Essa solução se embasou na teoria proposta para elaboração da EIDT, a partir de seis domínios baseados no MDM. A rotação oblíqua promax permite que os fatores da escala sejam correlacionados entre si (Damásio, 2012). Os seis fatores extraídos nessa solução explicavam $61,5 \%$ da variância. Nenhum item foi excluído das análises nesse momento, apesar de alguns apresentarem carga fatorial limítrofe. Todavia, essa análise ainda não sustentava uma solução adequada para explicar os componentes da escala, visto que havia cargas fatoriais complexas, com muitos itens que saturavam consideravelmente em mais de um fator e estavam muito dispersos entre os componentes do instrumento. Os itens do sexto fator possuíam, ainda, cargas fatoriais mais altas em outros fatores. Além disso, a leitura pormenorizada dos itens por fator não permitiu que eles fossem diferenciados e nomeados a partir de seus conteúdos. Dessa forma, não foi possível aceitar a solução de seis fatores, apresentada como ideal, considerando-se as seis dimensões (capacidades intelectuais, criatividade, competência social, inteligência prática, capacidades artísticas/musicalidade e capacidades psicomotoras) que fundamentaram a elaboração de itens. Como exemplo da análise desses itens, pode-se citar que os itens "possui grande facilidade em compreender implicações, por exemplo, entender que determinada ação gera determinada consequência" (capacidade intelectual), "toca algum instrumento musical ou gostaria muito de tocar, se tivesse oportunidade" (capacidades artísticas/musicalidade) e "ao se relacionar com outras pessoas, é educado(a), consegue dizer "por favor", "obrigado(a)", "desculpas" sem maiores dificuldades" (competência social), apareceram com cargas fatoriais no Fator 6, não permitindo, portanto, a nomeação do fator.

Assim, seguiram-se outras análises, buscando uma solução que explicasse melhor os componentes da escala e que possibilitassem a nomeação de fatores por meio da similaridade de conteúdos entre os itens. Nas análises seguintes, solicitou-se a extração de cinco e quatro fatores, com rotações promax e suprimindo as cargas fatoriais menores que 0,35 (Hair, Black, Babin, Anderson, \& Tatham, 2009). A solução com cinco fatores explicava $59,0 \%$ da variância e continuava com itens muito dispersos entre os componentes do instrumento, sem possibilidade de nomeação de fatores a partir dos pressupostos teóricos. Por exemplo, o Fator 4 dessa solução incluía os itens "sempre pensa de forma diferente dos colegas" (criatividade) e "tem ótimo desempenho em atividades físicas e/ou esportivas" (capacidades psicomotoras).

A solução com quatro fatores explicava $56,2 \%$ da variância e apresentava bom carregamento dos itens entre os fatores. Nessa última solução, 26 itens foram excluídos por apresentarem carga fatorial menor que 0,35 ou por carregarem muito semelhantemente em mais de um fator. Convencionou-se uma diferença mínima de 0,20 entre as cargas fatoriais para decidir a qual componente o item pertenceria (Hair et al., 2009). O Fator 1 ficou composto por 43 itens, o Fator 2 por dez itens, o Fator 3 por nove itens e o Fator 4 também 
por dez itens. Ainda considerando esta solução com quatro fatores, a análise da consistência interna de cada fator, calculada por meio do alfa de Cronbach (Maroco \& Garcia-Marques, 2006), revelou índices de bom a excelente. Respectivamente, para os fatores de 1 a 4 , os valores de alfa foram 0,981, 0,907, 0,818 e 0,833. Todavia, os valores do alfa do terceiro e do quarto fator aumentariam se fossem excluídos dois itens do terceiro fator e um item do quarto fator.

Por esse motivo, procedeu-se a uma nova análise fatorial com rotação Promax, com uma solução com quatro fatores e excluindo, nessa análise, os 26 itens que obtiveram cargas fatoriais menores que 0,35 na análise anterior ou grande saturação entre os componentes. Nessa nova análise, a variância explicada total aumentou para 57,4\%. Outros seis itens foram excluídos por apresentarem cargas fatoriais menores que 0,35 ou por saturarem muito semelhantemente em mais de um fator.

Como ainda havia alguma dispersão dos itens entre os componentes, uma outra análise foi feita, forçando-se novamente uma solução com quatro fatores e agora excluindo os 32 itens que apresentaram cargas fatoriais menores que 0,35 ou muita saturação entre os fatores nas análises anteriores. A variância explicada total novamente aumentou, sendo 58,6\% nessa última análise. Mais um item deveria ser excluído por não apresentar carga fatorial superior a 0,35 . Os Fatores 3 e 4 inverteram de posição, devido à variância explicada do terceiro fator (nas análises anteriores) ter sido reduzida nessa última AFE. A análise de consistência interna dos fatores também demonstrou que o valor do alfa de Cronbach dos Fatores 3 e 4 aumentaria se um item fosse excluído em cada um deles. Além disso, o alfa de Cronbach do Fator 4 foi de 0,710 e este fator contava, apenas, com quatro itens. Como este valor do alfa estava no limite aceitável e o fator contava apenas com quatro itens, realizou-se uma nova AFE, dessa vez forçando-se uma solução de três fatores, dadas as justificativas apresentadas.

Portanto, a análise foi feita solicitando-se a extração de três fatores, com rotação promax e excluindo, agora, as cargas fatoriais menores que 0,40 a fim de melhorar o refinamento dos itens entre os componentes. Nessa AFE, foram excluídos os 33 itens que não apresentaram as cargas fatoriais mínimas nas análises anteriores. A variância explicada total agora diminuiu, sendo $54,8 \%$, porém os itens se apresentavam com melhor distribuição entre os componentes da escala. Observou-se, ainda, que quatro itens deveriam ser excluídos por apresentarem cargas fatoriais menores que 0,40 e outros três por apresentarem saturação muito semelhante em mais de um fator. Os quatro itens que compunham o quarto fator, na última análise, passaram a fazer parte do fator 1. A AFE realizada com três fatores pareceu explicar melhor os resultados encontrados. Por isso, ela foi aceita como a solução mais adequada, encerrando-se, assim, as análises dos componentes da escala.

O Fator 1 se constituiu por 42 itens (Tabela 1), explicando $44,8 \%$ da variância da escala e com valor do alfa de Cronbach de 0,978 . O Fator 2 foi composto por nove itens, explicando $5,0 \%$ da variância da escala e apresentando alfa de Cronbach de 0,897. O Fator 3 englobou sete itens, também explicando $5,0 \%$ da variância da escala e alfa de Cronbach de 0,808. A análise de consistência interna do terceiro fator demonstrou que se o item 33 fosse excluído, o valor do alfa aumentaria para 0,838 . Por isso, o item em questão foi eliminado, a fim de purificar o fator.

Durante todas as análises realizadas, 41 itens foram excluídos por critérios estatísticos (baixa carga fatorial, alta saturação entre os componentes da escala ou aumento do valor do alfa de Cronbach do fator caso o item fosse excluído). Além da análise quantitativa, procedeu-se a uma análise qualitativa dos itens restantes, a fim de auxiliar na definição e nomeação dos fatores da escala.

A avaliação qualitativa dos componentes da escala apontou que os itens 42 e 64, apesar da boa estrutura fatorial encontrada na última AFE realizada, deveriam ser excluídos do Fator 2 por serem relacionados a capacidades artísticas/musicalidade. A exclusão desses itens tornaria o Fator 2 bastante puro, em critérios psicométricos, e incluindo somente itens relativos a capacidades psicomotoras (Tabela 2). Com a eliminação desses dois itens do Fator 2, o valor do alfa de Cronbach deste fator aumentou para 0,875 . O valor do alfa para toda a escala foi de 0,978 e não aumentaria caso algum item fosse eliminado. De acordo com Maroco e Garcia-Marques (2006), todos os valores de alfa de Cronbach encontrados são excelentes e indicam elevada consistência interna.

Considerando todas as análises realizadas, quantitativas e qualitativas, foram eliminados 43 itens da EIDT, que estava composta até então por 98 itens. A nova versão da EIDT inclui os 55 itens restantes, divididos em três fatores. O primeiro fator ficou composto por 42 itens, o segundo fator por sete itens o terceiro fator por seis itens. Portanto, os três fatores da EIDT 
Tabela 1

Itens do Fator 1 da EIDT e suas Respectivas Cargas Fatoriais

Itens do Fator 1 - Capacidades intelectuais, sociais e criatividade Carga fatorial

Planeja as atividades diárias de modo a não prejudicar seu tempo.

0,834

Consegue se dar bem em uma situação do dia a dia sem, necessariamente, ter conhecimento

0,619

técnico para isso.

Frequentemente termina as atividades escolares antes dos colegas.

0,754

É capaz de recordar informações importantes, que lhe foram passadas há bastante tempo.

0,501

Diante de um desafio cotidiano, avalia soluções para saber qual a mais adequada.

0,675

Possui grande facilidade em compreender implicações, por exemplo, entender que determinada

0,575 ação gera determinada consequência.

Consegue facilmente estabelecer vínculos positivos com outras pessoas.

0,418

É capaz de generalizar regras aprendidas com grande facilidade.

0,522

Monitora planejamentos feitos a fim de garantir o sucesso do resultado final.

0,751

Aprende rapidamente matérias relacionadas com linguagem e conteúdos verbais (como

0,786

Português, História, Geografia).

É precoce em algumas áreas do desenvolvimento ou do aprendizado (por exemplo, aprendeu

0,614 mais rapidamente a ler ou fazer contas).

Tem facilidade para compreender a linguagem escrita.

0,788

Quando está diante de um conflito com outra pessoa, consegue analisar diferentes soluções para

0,652 escolher qual a mais adequada à situação.

Ao se relacionar com outras pessoas, é educado(a), consegue dizer "por favor", "obrigado(a)",

0,624

"desculpas" sem maiores dificuldades.

É capaz de perceber relações complexas entre situações e objetos, fazendo comparações, por

0,456 exemplo.

Consegue apreender e fazer uso da informação aprendida nas aulas em um curto período de tempo.

Tem um raciocínio muito mais rápido que os colegas da mesma idade.

0,742

Tem grande quantidade de ideias.

0,691

0,545

Possui grande facilidade em aprender conceitos.

0,761

Se envolve profundamente com tarefas do dia a dia.

0,863

Se preocupa bastante com todo o grupo.

0,648

A expressão oral (comunicações, apresentações, etc.) é bastante original.

0,499

Aprende mais rapidamente que os colegas da mesma idade.

0,923

É capaz de resolver problemas de forma inovadora.

0,801

É capaz de reconhecer o significado de muitas palavras, tendo um amplo vocabulário.

0,743

Expressa suas opiniões e sentimentos sem magoar outras pessoas.

0,674

Consegue facilmente se colocar no lugar de outra pessoa para melhor entendê-la.

0,673

É capaz de lidar com críticas vindas de outras pessoas.

0,638

É capaz de pensar em várias soluções para um único problema do dia a dia, escolhendo aquela

0,671 que se encaixa melhor em determinado contexto.

Usa objetos e situações de forma incomum, dando-lhes outras atribuições, além das que já lhes

0,476 cabem. 
Tabela 1

Itens do Fator 1 da EIDT e suas Respectivas Cargas Fatoriais (Continuação)

\begin{tabular}{lc}
\hline Itens do Fator 1 - Capacidades intelectuais, sociais e criatividade & Carga fatorial \\
\hline Se interessa e se motiva por atividades que explorem as artes (por exemplo: música, dança, & 0,736 \\
pintura, teatro, etc.). & 0,717 \\
Consegue completar um desenho já começado de forma original e inovadora. & 0,905 \\
Parece ter uma motivação interna natural para realizar tarefas do dia a dia. & 0,580 \\
Possui grande facilidade em realizar atividades motoras finas, como recortar, desenhar, pintar, & 0,550 \\
escrever, digitar etc. & 0,708 \\
Critica construtivamente outras pessoas, sem ofendê-las, por algo que poderiam ter feito melhor. & 0,523 \\
Se mostra sábio(a) para lidar com situações cotidianas. & 0,781 \\
É capaz de aprender com as experiências da vida, desenvolvendo habilidades para lidar com & 0,581 \\
diferentes situações. & 0,682 \\
Aprende rapidamente matérias relacionadas com números e raciocínio lógico (como Matemática, & 0,477 \\
Física, Química). & 0,787 \\
Consegue completar uma frase ou parte faltante de um texto de forma original e inovadora. & É muito rápido(a) para executar tarefas intelectuais e acadêmicas de pouca dificuldade. \\
É querido(a) e aceito(a) pela maioria dos colegas e pessoas com quem convive. & \\
Coopera com colegas ou professores sem nenhuma dificuldade. &
\end{tabular}

Tabela 2

Itens do Fator 2 da EIDT e suas Respectivas Cargas Fatoriais

\begin{tabular}{lc}
\hline Itens do Fator 2 - Capacidades psicomotoras & Carga fatorial \\
\hline Se interessa facilmente por tarefas que envolvem movimentos ou atividades corporais. & 0,752 \\
Faz ótimo uso do corpo e de sua postura de acordo com sua idade e desenvolvimento. & 0,763 \\
É capaz de usar o próprio corpo na solução de problemas e no enfrentamento de desafios com & 0,879 \\
facilidade. & 0,773 \\
$\begin{array}{l}\text { Possui grande facilidade em realizar atividades motoras amplas, como dançar, correr, jogar bola, } \\
\text { praticar esportes etc. }\end{array}$ & 0,625 \\
$\begin{array}{l}\text { É capaz de se expressar com facilidade por meio de movimentos corporais. } \\
\text { Quando conversa com outras pessoas, faz muito uso de expressões faciais e gestos. }\end{array}$ & 0,880 \\
Ao conversar com um colega ou professor, é capaz de manter contato visual e físico, sorrir, & 0,800 \\
gesticular, se despedir, fazendo isso com bastante facilidade. & \\
\hline
\end{tabular}

foram nomeados como: Fator 1) Capacidades intelectuais, sociais e criatividade: inclui itens relativos aos preditores capacidades intelectuais, criatividade, competência social e inteligência prática do MDM; Fator 2) Capacidades psicomotoras: inclui itens unicamente do preditor de mesmo nome no MDM; Fator 3) Capacidades artísticas: inclui itens referentes aos preditores capacidades artísticas e musicalidade do MDM (Tabela $3)$.

A variância explicada que se encontrou para o Fator 1 pode indicar um único fator subjacente à escala, por ser maior que $30 \%$. O método de rotação oblíqua utilizado não favorece tanto a superestimação da variância (Damásio, 2012), podendo-se atribuí-la, portanto, a 
Tabela 3

Itens do Fator 1 da EIDT e suas Respectivas Cargas Fatoriais

\begin{tabular}{lc}
\hline Itens do Fator 3 - Capacidades artísticas & Carga fatorial \\
\hline Toca algum instrumento musical (ou gostaria muito de tocar, se tivesse oportunidade). & 0,524 \\
Pode-se dizer que é muito bom “de ouvido". & 0,726 \\
Possui grande facilidade para discriminar sons (notas musicais, intensidade, timbres, ritmos). & 0,818 \\
Possui grande facilidade para reconhecer melodias, timbres e ritmos. & 0,732 \\
Possui grande facilidade para se expressar artisticamente, seja por meio de desenhos, pinturas, & 0,565 \\
poesias, músicas, danças ou outras produções artísticas. & 0,483 \\
É muito sensível a diferentes expressões artísticas de outras pessoas. & \\
\hline
\end{tabular}

outras condições. Além disso, o Fator 1 agrupou itens pertencentes a quatro preditores do MDM, para os quais foram originalmente elaborados (Freitas, 2016), apresentando também elevada porcentagem de variância explicada de 44,8\%. Situação diferente ocorreu com os itens dos Fatores 2 e 3, que envolveram exclusivamente itens sobre capacidades psicomotoras e artísticas, assim como os preditores análogos descritos no MDM. Pode-se presumir que os itens do Fator 1 são os mais facilmente avaliados pelos professores regentes, pois se relacionam a comportamentos amplamente observados em sala de aula. Provavelmente, por esse motivo, os itens de quatro diferentes preditores do MDM se agruparam em um mesmo componente.

Esse resultado converge com dados de outras pesquisas sobre nomeação por professores. Farias, Weschler e Weschler (2011) encontraram após a nomeação por professores realizada com instrumento próprio, um percentual de $74 \%$ de alunos identificados na área da inteligência. Para as autoras, essa avaliação docente é tendenciosa, na medida em que o professor indica somente alunos que se destacam em atividades cognitivas e acadêmicas. Chiodi, Farias e Weschler (2011) também destacam que os professores tendem a avaliar positivamente alunos com bom desempenho, que não atrapalham a prática do professor e a sala de aula. $\mathrm{O}$ desempenho acima da média não pode ser considerado, de forma solitária, como um indicativo da presença de D\&T.

Nesse sentido, é plausível que os professores que participaram dessa pesquisa tenham avaliado os alunos de modo enviesado e tendencioso, o que configura-se nos resultados da análise fatorial da EIDT representada por três fatores que não condizem com a estrutura teórica que embasou a construção do instrumento. $\mathrm{O}$ viés na avaliação pode ter sido decorrente do pouco tempo dispendido para capacitação dos professores, haja vista que trabalhos como o de Guenther (2006) enfatizam a necessidade de submeter os docentes a um treino específico sobre características de D\&T.

O trabalho de Siegle e Powell (2004) explorou os vieses que os professores têm durante a nomeação de alunos com D\&T. Dentre eles, os autores destacam gênero, especificidade do critério de seleção e atenção maior às vulnerabilidades que às potencialidades dos alunos. A especificidade do critério de seleção pode ser considerada como o viés principal dos professores respondentes da EIDT, pois associaram fortemente o desempenho acadêmico e habilidades relacionadas a ele com as características de D\&T (o que está incluído no Fator 1 da EIDT, com maior variância), em detrimento de outras capacidades como as artísticas, as psicomotoras e criatividade relacionada a essas tarefas (que se distribuíram entre os Fatores 2 e 3).

\section{Considerações Finais}

Este trabalho investigou as evidências de validade fatorial e a consistência interna da Escala de Identificação de Dotação e Talento (EIDT), elaborada por Freitas (2016) para identificar características de D\&T em alunos do Ensino Fundamental, por meio da nomeação de professores. Os resultados encontrados se apresentam, de modo geral, satisfatórios para as propriedades psicométricas iniciais.

No entanto, algumas limitações podem ser observadas no estudo. Há que se apontar que não foi feita uma aplicação piloto da EIDT, dada a grande dificuldade de encontrar professores disponíveis para participação na pesquisa. A aplicação piloto poderia evitar, por exemplo, que alguns itens tivessem muitos valores omissos por dificuldades de interpretação ou de entendimento, 
o que poderia alterar os resultados encontrados nas análises fatoriais realizadas.

Sugere-se também a necessidade da continuidade de pesquisas com a escala, de modo que outras evidências de validade possam ser avaliadas, ampliando as amostras e os contextos de investigação. Podem-se citar, por exemplo, a necessidade de estudos de validade convergente, com uma escala semelhante como a Gifted Rating Scale (Nakano \& Siqueira, 2012), e de validade preditiva com o desempenho dos alunos, por exemplo. Além disso, deve-se ressaltar que os métodos de fatoração e extração das AFEs realizadas nesse estudo foram limitados.

Novos estudos ainda podem verificar se o Fator 1 da EIDT não comporia uma escala única e suficiente para o rastreio de características de D\&T em sala de aula e se os Fatores 2 e 3 poderiam ser aplicados em professores de educação física e artes, respectivamente. Esses professores deveriam ter uma visão mais apurada dos comportamentos expressos pelos itens avaliados pela EIDT que os professores regentes, o que proporcionaria novos resultados e novas evidências de validade aos estudos sobre D\&T em áreas pouco vislumbradas pelas escolas como essas. No mesmo sentido, a aplicação em uma amostra independente também se mostra fundamental porque viabilizaria a realização da análise fatorial confirmatória, que colaboraria para a efetiva definição do número de fatores, uma das maiores dificuldades deste estudo.

Além disso, não se pode deixar de cogitar a hipótese dos resultados encontrados, apesar de satisfatórios, serem baseados em uma avaliação pouco profunda e enviesada dos professores participantes. A despeito dos esclarecimentos feitos aos participantes acerca do tema antes da entrega da escala, reitera-se que não foi uma capacitação suficiente para que compreendessem o conceito avaliado e seus componentes. Sugere-se que pesquisas futuras sobre a temática se debrucem em uma capacitação prévia mais bem estruturada.

\section{Referências}

Barbosa, A. J. G., Schelini, P. W., \& Almeida, L. C. (2012). Medidas de dotação e talento: Produção científica em Psicologia (2006-2011). Em E. Boruchovitch, A. A. A. Santos \& E. Nascimento (Eds.), Avaliação psicológica nos contextos educativo e psicossocial (pp. 33- 52). São Paulo: Casa do Psicólogo.

Brasil. (2001). Resoluçãon. ${ }^{\circ}$ 02/2001, institui as Diretrizes Nacionais da Educação Especial para a Educação
Básica. Brasília: Conselho Nacional de Educação. Câmara de Educação Básica.

Campos, C. R., \& Nakano, T. C. (2012). Produção científica sobre avaliação da inteligência: o estado da arte. Interação Psicol., 16(2), 271-282.

Chiodi, M. G., Farias, E. S., \& Weschler, S. M. (2011). Percepção docente acerca do aluno inteligente e criativo. Revista Intellectus, 17, 29-39.

Conselho Federal de Psicologia. (2003). Resolução 002/2003, define e regulamenta o uso, a elaboração e a comercialização de testes psicológicos e revoga a Resolução CFP n 025/2001. Brasília: Conselho Federal de Psicologia.

Damásio, B. F. (2012). Uso da análise fatorial exploratória em psicologia. Avaliação Psicológica, 11(2), 213-228.

Farias, E. S., Weschler, A., \& Weschler, S. M. (2011). Dotação e talento: Nomeação por professores e pares. Revista Intellectus, 17, 98-104.

França-Freitas, M. L. P, Del Prette, A., \& Del Prette, Z. A. P. (2014). Social skills of gifted and talented children. Estudos de Psicologia, 19(4), 288-295.

Freitas, M. F. R. L. (2016). Escala de identificação de dotação e talento: Construção de instrumento e validade de conteúdo (Tese de doutorado). Centro de Ciências Humanas e Letras, Universidade Federal de São Carlos, São Paulo.

Gagné, F. (2013). The DMGT: Changes within, beneath, and beyond. Talent Development \& Excellence, 5(1), 5-19.

Gardner, H., Chen, J., \& Moran, S. (2010). Inteligências múltiplas ao redor do mundo. Porto Alegre: Artmed.

Guenther, Z. C. (2006). Dotação e talento: reconhecimento e identificação. Cadernos de Educação Especial, 28. Recuperado de: https://periodicos.ufsm.br/ educacaoespecial/article/view/4281/2529

Hair, J. F., Black, W. C., Babin, B. J., Anderson, R. E., \& Tatham, R. L. (2009). Multivariate data analysis: a global perspective. $7^{\text {th }}$ ed. Upper Saddle River: Prentice Hall.

Hedlund, J., \& Sternberg, R. J. (2002). Inteligências em excesso? Integrando as inteligências social, emocional e prática (R. C. Costa, Trad.). Em R. Bar-On \& J. D. A. Parker (Eds.). Manual de inteligência emocional (pp. 111-131). Porto Alegre: Artmed.

Psico-USF, Bragança Paulista, v. 22, n. 3, p. 473-484, set./ dez. 2017 
Heller, K. A. (2004). Identification of gifted and talented students. Psychology Science, 46(3), 302-323.

Heller, K. A. (2005). Education and counseling of the gifted and talented in Germany. International Journal for the Advancement of Counseling, 27(2), 191-210.

Heller. K. A. (2007). Scientific ability and creativity. High Ability Studies, 18(2), 209-234.

Heller, K. A. (2012). Different research paradigms concerning giftedness and gifted education: shall ever they meet? High Ability Studies, 23(1), 73-75.

Heller, K. A., \& Perleth, C. (2008). The Munich High Ability Test Battery (MHBT): A multidimensional, multimethod approach. Psychology Science Quarterly, 50(2), 173-188.

Heller, K. A., Perleth, C., \& Lim, T. K. (2005). The Munich Model of Giftedness designed to identify and promote gifted students. Em R. J. Sternberg \& J. E. Davidson (Eds.), Conceptions of Giftedness, $2^{\mathrm{a}} \mathrm{ed}$. (pp. 147-170). New York: Cambridge University Press.

Horn, J. L. (1965). A rationale and technique for estimating the number of factors in factor analysis. Psychometrika, 30(1), 179-185.

Horowitz, F. D. (2009). Introduction: A developmental understanding of giftedness and talent. Em F. D. Horowitz, R. F. Subotnik, D. J. Matthews (Eds.), The development of giftedness and talent across the life span (pp. 3-19). Washington, DC: American Psychological Association.

International Test Commission (2000). ITC guidelines on test use. Recuperado de http:/ /www.intestcom.org/ files/guideline_test_use.pdf.

Kim, K. H. (2011). The creativity crisis: The decrease in creative thinking scores on the Torrance Tests of Creative Thinking. Creativity Research Journal, 23(4), 285-295.

Kline, R. B. (2005). Principles and practice of structural equation modeling. $3^{\text {rd }}$ ed. New York: Guilford Press.

McGrew, K. S. (2009). CHC theory and the human cognitive abilities project: Standing on the shoulders of the giants of psychometric intelligence research. Intelligence, 37, 1-10.
Maroco, J., \& Garcia-Marques, T. (2006). Qual a fiabilidade do alfa de Cronbach? Questões antigas e soluções modernas. Laboratório de Psicologia, 4(1), 65-90.

Nakano, T. C., \& Siqueira, L. G. C. (2012). Validade de conteúdo da Gifted Rating Scale (versão escolar) para a população brasileira. Avaliação Psicológica, 11(1), 123-140.

Nisbett, R. E., Aronson, J., Blair, C., Dickens, W., Flynn, J., Halpern, D. F., \& Turkheimer, E. (2012). Intelligence: New findings and theoretical developments. American Psychologist, 67, 130-159.

Pfeiffer, S., \& Jarosewich, T. (2003). Gifted Rating Scales - Manual. San Antonio, TX: Pearson.

Prieto, G., \& Muñiz, J. (2000). Un modelo para evaluar la calidad de los test utilizados en España. Papeles del Psicólogo, 77, 65-75. Recuperado de http://www. papelesdelpsicologo.es $/$ vernumero.asp?id $=1102$

Ross, P. O. (1993). National excellence: A case for developing America's talent. Washington, DC: U.S. Department of Education, Office of Educational Research and Improvement.

Siegle, D., \& Powell, T. (2004). Exploring teacher biases when nominating students for gifted programs. Gifted Child Quarterly, 48(1), 21-29.

Sternberg, R. J., \& Davidson, J. E. (Eds.) (2005). Conceptions of giftedness, $2^{\text {nd }}$ ed. New York: Cambridge University Press.

Stoeger, H., Steinbach, J., Obergriesser, S., \& Matthes, B. (2014). What is more important for fourthgrade primary school students for transforming their potential into achievement: The individual or the environmental box in multidimensional conceptions of giftedness? High Ability Studies, 25(1), 5-21.

Topping, K., Bremner, W., \& Holmes, E. A. (2002). Competência social: A construção social do conceito (R. C. Costa, Trad.). Em R. Bar-On \& J. D. A. Parker (Eds.). Manual de inteligência emocional (pp. 39-46). Porto Alegre: Artmed.

Recebido em: 15/07/2015

Reformulado em: 14/06/2016;

Aprovado em: 05/09/2016 
Sobre os autores:

Márcia de Fátima Rabello Lovisi de Freitas é graduada, mestre em Psicologia pela Universidade Federal de Juiz de Fora e doutora em Psicologia pela Universidade Federal de São Carlos.

E-mail: marciafreitaspsi@gmail.com

Patrícia Waltz Schelini é doutora em Psicologia pela Pontifícia Universidade Católica de Campinas. pós-doutora pela Universidade do Minho (Portugal), sob a orientação do Prof. Dr. Leandro da Silva Almeida. Atualmente é professora do Departamento de Psicologia da Universidade Federal de São Carlos, onde ministra aulas na graduação e na pósgraduação e desenvolve estudos sobre a inteligência/cognição, metacognição e pensamento imaginativo.

E-mail: patriciaws01@gmail.com

Edgardo Raúl Pérez é doutor em Psicologia pela Universidad Nacional de Córdoba, Argentina. Atualmente é professor da Facultad de Psicología da Universidad Nacional de Córdoba, Argentina, onde ministra aulas na graduação e na pós-graduação e desenvolve estudos sobre dotação e talento, inteligências múltiplas, teoria social cognitiva e psicometria.

E-mail: edrapester@gmail.com

\section{Contato com os autores:}

Universidade Federal de São Carlos, Centro de Ciências Humanas, Departamento de Psicologia

Rodovia Washington Luís, km 235

São Carlos-SP, Brasil

CEP: 13565-905 